\title{
Networked Microgrids for Reliable Load Sharing in Remote locations of Armed Force
}

\section{CPS Pasricha ${ }^{1}$, Rajeev Gupta ${ }^{2}$, Rahul Walawalkar ${ }^{3}$}

${ }^{1}$ Department of Electrical Engineering, University of Petroleum and Energy Studies, Dehradun, India

${ }^{2}$ Department of Physics, University of Petroleum and Energy Studies, Dehradun, India

${ }^{3}$ Executive Director, IESA \& President \& MD,Customized Energy Solutions,Pune, India.

Article History: Received: 10 January 2021; Revised: 12 February 2021; Accepted: 27 March 2021; Published online: 10 May 2021

\begin{abstract}
Forward operating bases of the Armed Forces are located in remote areas where grid connection is normally not available and if available are vulnerable to outages due to vagaries of weather or action by adversary. Microgrids are generally more efficient and may provide electric power storage for emergency supply of electricity to mission critical equipment like surveillance systems, sensors, communication, command and control systems of such forward bases. Several small independent microgrids can also be interconnected together to satisfy the energy requirements of the remote military areas. Networking of several self-supervised microgrids is being developed with the aim to enhance efficiency, reliability and resiliency as well as the steadiness of power systems. In this work, an interconnection of microgrids at three remote bases of the armed forces is presented and simulated. The proposed power co-ordination strategy is designed in such a way that during peace time operation it tries to minimize the overall requirement of fossil fuel for generators supplying the critical loads and in case of outages, it can tackle the emergency situation by automatically routing the power to critical loads from other operational bases. The entire system has been simulated and verified using MATLAB 2018.
\end{abstract}

Keywords-Power co-ordination, networked microgrid, PV system, diesel generator, battery system, critical loads, military remote areas.

\section{INTRODUCTION}

Supplying electricity to remote areas is a challenge due to inaccessible areas and economic factors, it is even more challenging for far-flung bases of the Armed Forces which are invariably located towards the end of the transmission lines and in unreachable areas. The electrical needs of remote military areas can be supplied by small distributed energy resources in an islanded scheme, integrated by a controller. Hence, their power systems can be considered as a microgrid, operating independently and isolated. The structure of these microgrids should be so designed that adequate generation capacity is available within their local distributed energy resources to meet their needs. All across the world there is significant and widespread deployment of microgrid and is anticipated to grow in the future, this has led to better and efficient designs of microgrids including economical operation of a cluster or a network of interconnected microgrids. Coordinated operations of multiple microgrids which are interconnected can be called as networked microgrids. Networking of multiple microgrids to other microgrid or grids can be more reliable and economical to the users specially in remote areas [1]. Interconnected microgrids can be studied from different perspectives. Economic benefits of interconnected microgrids are discussed in [2] in which it is highlighted that their operation leads to reduction in emissions and cost to the users while addressing the load growth. With modern control and communication technologies the operations of networked microgrids is coordinated with the distribution system to meet the daily ever increasing needs more efficiently. The main advantages is during emergencies or natural calamities, where the critical needs of healthcare, communications can be met for longer durations and microgrids can restore power supply to the grid, which may also include black-start support to conventional power stations [3]. The energy management and coordination amongst microgrids become more challenging since various types of uncertainties, such as load variation, wind, and solar power generations variation are the factors involved in the assessment [4]. Consideration of energy storage systems, such as batteries, supercapacitors, and flywheels increases the operational complexity of the network system.

One of the most challenging tasks in controlling the process of networked microgrids in coordination with distributed system operators is issues of security, privacy and uncertainties. For optimal and efficient energy management, operation and control of networked microgrids, several approaches have been evolved in coordination with operators of the system. As a part of network of interconnected microgrids, a smaller independent microgrid may have a different operator and each can be responsible for supplying the demand of a particular zone of the remote area. In [5], a cooperative and dynamic power dispatch strategy to economically meet the load demands with multiple microgrids within a distributed system have been evolved. The problem of dynamic economic dispatch of multiple microgrids for minimizing the PV power limitation while maintaining the privacy of microgrids has been presented in [6]. A multi-objective economic power-sharing problem of networked microgrids considering energy storage systems at each microgrid has been proposed in [7]. Design and control of interconnected and networked microgrids has been studied by a number of researchers and several strategies have been published. In [8], a coordinated control strategy for the operation of networked microgrids and distribution systems has been developed. To coordinate power exchange between microgrids and distribution systems, a two-stage decentralized energy management framework based on the alternating direction method of multipliers (ADMM) has been discussed in [9]. Various uncertainties related to Distributed Energy Resources and loads at each microgrid have been modelled using Monte Carlo simulations and solved using robust 
optimization. A multi-layer control architecture has been developed for the voltage and frequency control of networked microgrids in [10] by utilizing voltage source converter and adaptive droop control. Resiliency improvement is one of the major advantages of networked microgrids. To improve the resiliency of networked microgrids against natural disaster, a resilient distribution system planning based on robust optimization model has been studied in [11]. In the successful operation of networked microgrids, power electronics devices and communication links are a major factor has been discussed in [12]. However, these are highly vulnerable to cyber-attacks. Therefore, the system must be adequately attack-resilient, and trust-based communication and control protocols have to be utilized [13]. Microgrids of armed forces are more vulnerable to such cyber attacks which can have a devastating affect on energy needs of remote bases. The study in [14] two microgrids are analysed which are isolated from the utility grid but in a peer-to-peer manner, can exchange energy with each other with the objective of minimising the total cost resulting from energy generation and exchange, while the local energy demand is satisfied by each microgrid.

In [15], a microgrid cluster control system is proposed and implemented using Multi Agent System for communication and control among a number of adjacent microgrids. The study in [16] presents a unique microgrid network with a distributed control oriented hierarchical system and distributed Multi Agent System architecture. In [17], a three level control of microgrid cluster is demonstrated: local microsource and load controller, microgrid central controller, and distribution management system. The control of this system is done by a central autonomous management controller, which aids as an interface to the distribution management system. In [18], a hierarchical and decentralized scheme is proposed for coordinated voltage support and frequency control, as well as for state estimation of microgrid clusters.

Networked microgrids is referred to the interconnection of two or more microgrids with an capability to connect distribution system to exchange power amongst the microgrid and/or the distribution system at the Point of Common Coupling [19]. The operation of clusters of microgrids in the arrangement of networked microgrids is possibly the best way to utilize distributed energy resources. Also, during emergencies, this can extend the duration of supply to the critical demands or loads and supports black start to nearby generating station [20]. Thus, resiliency and reliability of the complete system are enhanced significantly [21]. Independent microgrids can be of direct current (DC) or alternating current (AC) depending on the local power generation, demand and the specific requirement of loads, especially in remote areas. Although, AC microgrids are dominant in the present-day scenario, however, DC microgrids are getting more acceptance because of the production of power generation from PV panels and increasing DC loads (such as communication equipment, LED lights, computers, sensors and other DC appliances) [22]. Networked microgrids can model as a smart grid at a smaller scale where both AC and DC microgrids share loads economically, efficiently and optimally during all conditions of normal operations and emergency conditions. In standard operating condition, economic dispatch strategy is the primary aim for power exchange which has the objective of achieving minimum cost of supply [23]. In this case, all microgrids can work in an integrated mode either with other microgrids or in coordination with the main grid. In this way, the total power generated from distributed energy resources can be exploited to reduce the cost of energy. It also improves the reliability of the system, as deficit power of any microgrid can be supplied directly through the other microgrids which are having a surplus generation, or through the distribution system. Similarly, surplus power of any microgrid can be exported to the other microgrids or distribution system as per the finest possible choice available. In a condition when cumulative power generation from all microgrids is more than the total power demand of microgrids and distribution system, the excess power can also be sent to the main grid [24]. Thus, networked microgrids can reduce the cost of energy and improve the reliability of the complete system considerably [25]. In emergency operating conditions, when the main grid in not able to supply power, each microgrid alone can supply their own critical loads and together can add power to the distribution system and extend the duration of supplying power to critical loads. The coordinated operation of all microgrids in the form of a network can has the ability to feed the main grid for some time which will depend on the storage capacities and the backup capacity of various synchronous generators in each microgrid. Thus, networked microgrids has the ability to enhance the resiliency of the system significantly [26].

If implemented and managed properly, networked microgrids can provide a range of benefits to electric power utilities and consumers. Remote areas like islands, isolated military bases where grid supply is not feasible and even carriage of fuel for generators is also exorbitantly expensive are best benefitted by Networked microgrids which can provide critical and required emission-free power and other ancillary services such as voltage support, frequency regulation and emergency demand response. In addition, networked microgrids can improve the efficiency, sustainability, security, reliability, resilience, and economics of the electric power supplied to the customers [27]. The networked microgrid is not the same as the traditional power distribution network. The flow of power is bidirectional from one microgrid to another microgrid or distribution system and the change in network topology is frequent in networked microgrids. Also, the electrical inertia of the system is lesser and the variation in power generation is dynamic and sometimes unpredictable. 
Literature survey shows that immense work has been proposed for networking of microgrids for better economics. It has also been highlighted that overall quality and customer satisfaction can be improved by coordination amongst different small microgrids within any urban area. Taking lead from these studies, authors have thought of a similar arrangement of networking microgrids for remote locations of the Armed Forces to enhance reliability for critical loads. In recent work, authors have proposed a design for 1MW islanded microgrid system for remote locations of Armed Forces [28]. The generalized structure of the microgrid is shown in Fig. 1. The microgrid contains PV array for renewable energy generation, battery subsystem in order to provide backup and to maintain the DC link voltage at a predefined value. It also incorporates diesel generators as a backup power source in case battery power gets drained out. Voltage source inverter is used to convert the DC voltage from the source to 3-phase supply at load side. In this work authors have proposed a new scheme for interconnecting and networking microgrids established at different military bases as part of a larger military deployment. The bases are at some distance apart in remote locations and interconnected. Three different islanded microgrids with different capacities have been considered in this study. These three microgrids will be able to share power amongst each other with the help of common dc link line connecting them. Power sharing will be controlled with the help of a separate control scheme. The control scheme decides the quantum of power sharing between these three microgrids based on the power required by each, the specified critical loads and power available at the other base microgrid. The proposed scheme has been verified with different simulation studies for different cases. Apart from this, an emergency situation has been considered in which the entire power from the microgrids of two bases will be routed to critical loads of the third base considering the that power sources of the third base have been destroyed by military action.

The rest of the paper is arranged as follows: Section II describe the proposed system in detail, Section III presents the proposed control scheme for interconnection and networking of different microgrids, Section IV shows the effectiveness of the systems with the help of different simulation studies and Section V concludes the paper with future work to be done.

\section{SYSTEM DESCRIPTION}

In this paper authors have designed and simulated three interconnected microgrids on remote bases of Armed Forces. Figure 2 shows the block diagram of the system under observation. As shown in the Fig. 2, there are three different bases with corresponding microgrids of $1 \mathrm{MW}, 500 \mathrm{KW}$ and $200 \mathrm{KW}$ capacity. Area 1 (Mother base) and Area 2 are designated as operating bases in depth areas which are accessible and with normal electrical loads. Area 3 is a forward operating base in remote area with the critical loads like surveillance systems, communication systems, sensors etc which need uninterrupted power supply of accumulative load of $200 \mathrm{KW}$. Assured availability of power to this forward operating base with critical loads is to be guaranteed in the network. The same requirement has been fulfilled by maintaining continuous power supply at critical loads with the help of power co-ordination control strategies. Detailed description of each area and corresponding microgrid specifications have been described in this section.

\section{A. System Specifications}

As shown in the Fig. 2, all three microgrids have been connected to each other through common DC line. DC line is chosen to interconnect the microgrids for the following reasons:

- Power generation from renewable sources is in the form of DC voltage. Hence no additional converter is required.

- $\quad$ There is no need of additional synchronization equipment for DC link line.

- Material requirement for interconnection of microgrids will be less consuming lesser resources and cost.

- Time latency for interconnection will be less and maintenance of DC lines in case of any emergency situation will be easy.

Microgrids in all three bases work on similar electrical specifications. DC link voltage of the dc line remains at $665 \mathrm{~V}$ for all three bases. AC voltage at the load side in all three bases is set at $400 \mathrm{~V}$ rms. Voltage at DC link is maintained with the help of battery subsystems as shown in Fig. 1.

\section{B. PV System}

Primary power source in all three areas is solar energy. PV panels have been used in all areas to convert the solar energy into electrical energy. Output of the PV system is connected to the dc link as shown in Fig. 1. Total generation capacity of the PV system depends upon the number of PV panels employed in the system. Further, it should be noted that there is no extra unit for maximum power point tracking (MPPT) as PV system in all three areas is designed in such a way that there is no requirement for additional MPPT controller device. 


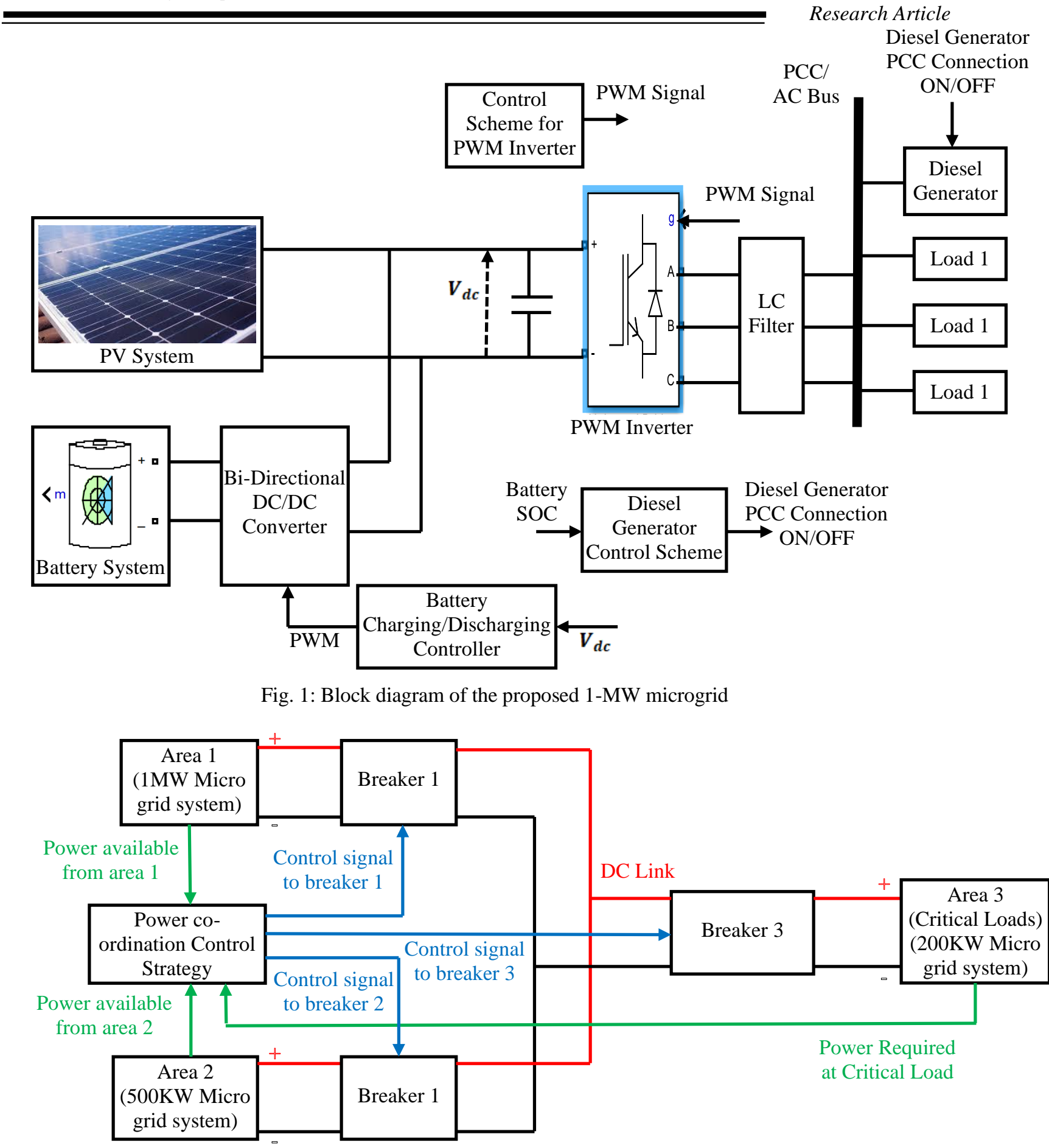

Fig. 2: Interconnection of different microgrids with common dc link and control strategy block.

In this study PV system of microgrid employed in all three areas have used 1Soltech 15TH-215-P solar panel modules. Each panel has an open circuit voltage of $29 \mathrm{~V}$ and $213.15 \mathrm{~W}$ output power at maximum power point (MPP). Figure 3 shows the series and parallel combination of the PV panels in order to achieve the required power from PV system. There are $\mathrm{N}$ panels connected in series and there are $\mathrm{M}$ such rows.

In the proposed design, PV panel has to be connected in series so that the DC link voltage across them remain near to the MPP open circuit voltage of the array. DC link voltage is maintained at $665 \mathrm{~V}$ and hence 23 solar panels were connected in series in order to achieve the MPP open circuit voltage of such array at 667V. By doing this, there is no need to connect additional MPPT controller at the output of the PV system. Further, parallel rows of these series connected PV panels is decided by overall power requirement.

Hence, for 1MW power capacity in Area 1, there is a need of a total of 4692 PV panels. In Area 1, 23 panels (N) are connected in series and there are 204 parallel rows (M) of such series connected arrays. Figure 4(a) shows the IV and PV characteristics of PV system for Area 1. For $500 \mathrm{KW}$ power capacity in Area 2, there is a need of 
total 2346 PV panels. In Area 2, series connected panels (N) are 23 and parallel rows (M) are 102. Figure 4(b) shows the IV and PV characteristics of PV system of Area 2. For $200 \mathrm{KW}$ power capacity in Area 3, there is a need of total $939 \mathrm{PV}$ panels. This requirement is approximated by having 23 panels in series $(\mathrm{N})$ and 41 parallel rows (M) of these series arrays. Finally, there are total 943 panel in the $200 \mathrm{KW} \mathrm{PV}$ system. Figure 4(c) shows the IV and PV characteristics of the PV system of Area 3 with critical loads.

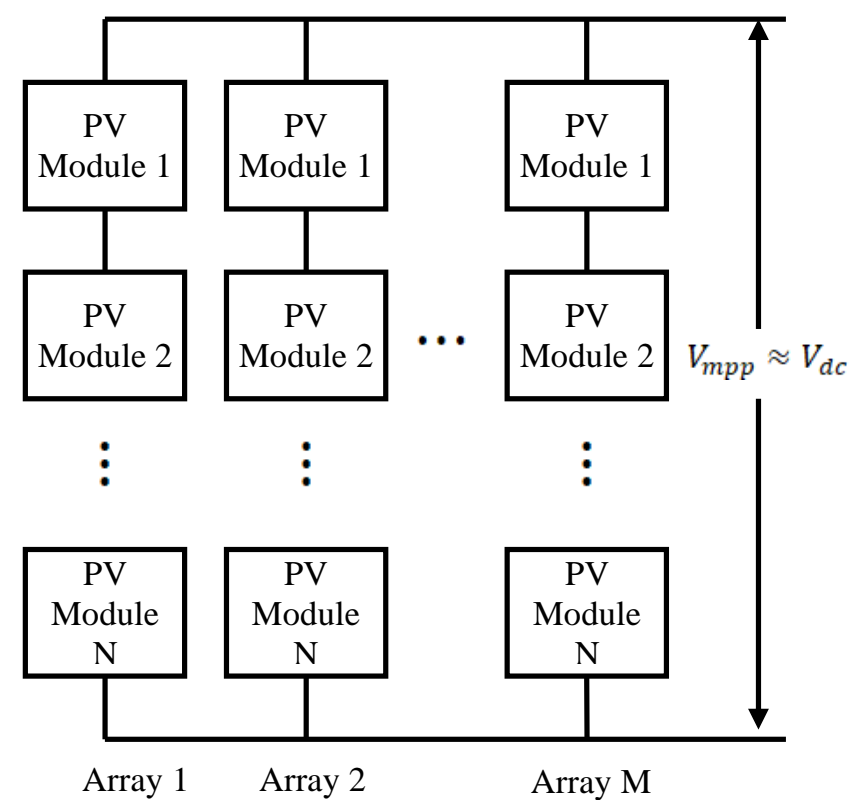

Fig. 3: Series and parallel combinations of the PV module to get the required solar power.
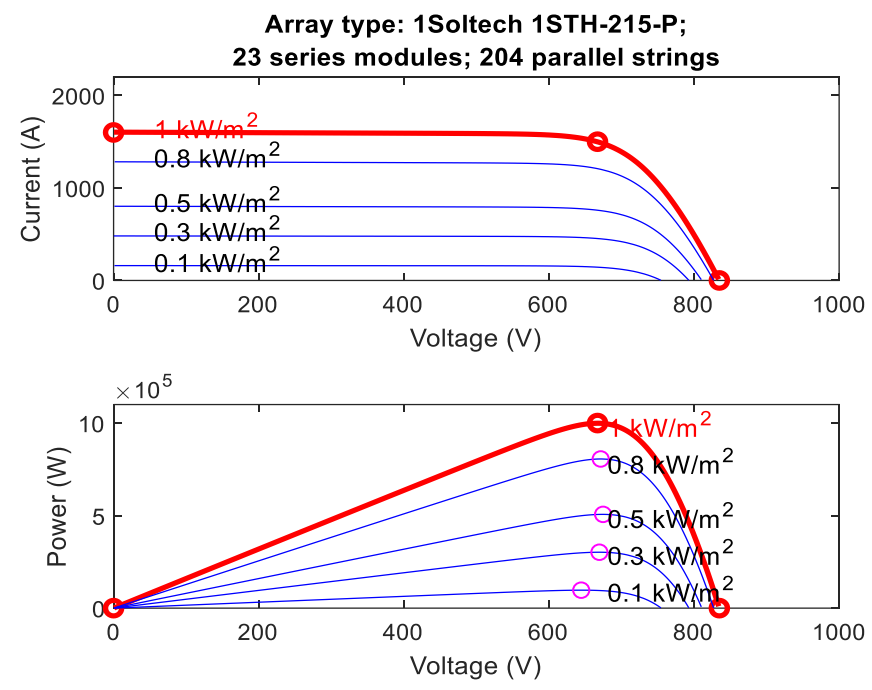

(a) 
Array type: 1Soltech 1STH-215-P;

23 series modules; 102 parallel strings
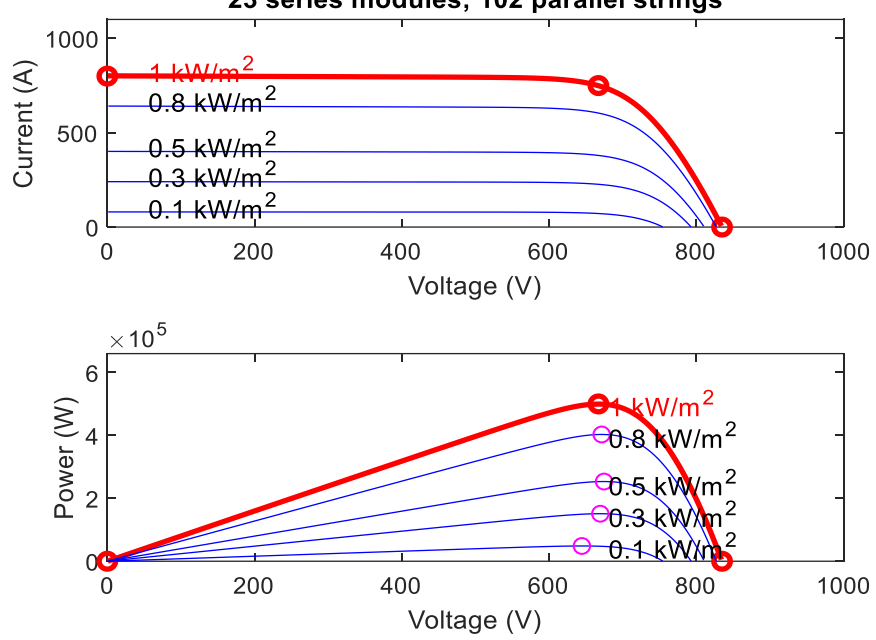

(b)
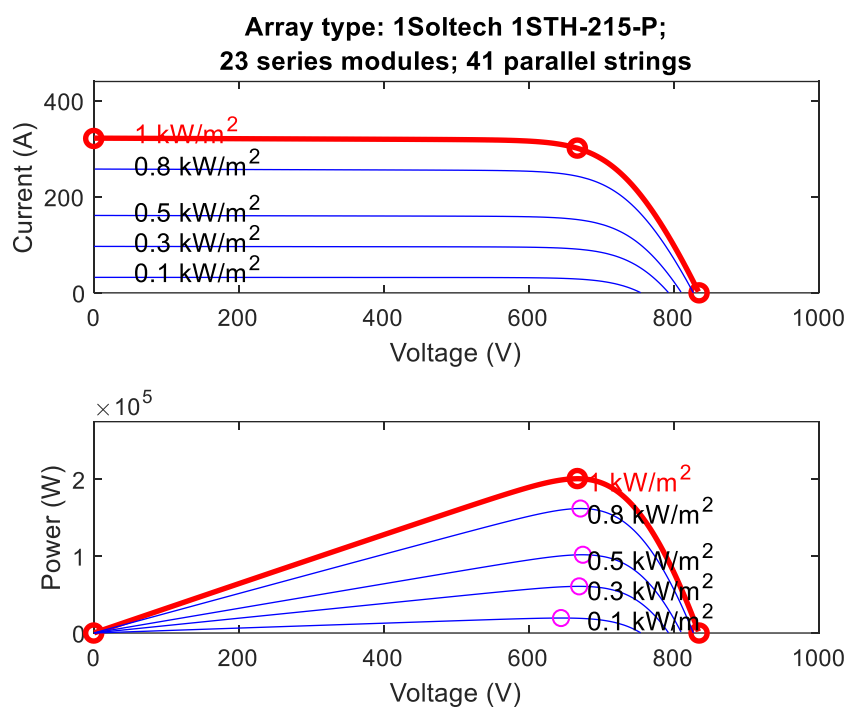

(c)

Fig. 4: Current v/s voltage and power v/s voltage curve of the PV system for different amount of irradiances (a) 1MW PV system (area 1), (b) 500KW PV system (area 2), (c) $200 \mathrm{KW} \mathrm{PV} \mathrm{system} \mathrm{(area} \mathrm{3).}$

\section{Battery System and Charging/Discharging Controller}

Battery management system is required as shown in Fig. 1, in order to control the DC link voltage with the help of charging and discharging of batteries. In this work each area employs the battery management system in order to maintain the DC link area at specified voltage levels. Figure 5 shows the battery discharging characteristics for each area during normal mode of operation. Control scheme presented in Fig. 6 has been used for the control of battery management system. Block diagram of the control scheme employed in each area is given by Fig. 6 .

Specifications of the energy storage system were different for each area depending upon the capacity of respective area. For Area 1 energy storage, a battery system of 500V and 3000Ah current capacity was used. Area 2 has the capacity of $500 \mathrm{KW}$ and battery system of $500 \mathrm{~V}$ and 1500Ah current capacity was considered. Battery system for Area 3 is $500 \mathrm{~V}$ and $600 \mathrm{Ah}$ current capacity. Further, in order to design the energy storage system with above mentioned specifications, series and parallel combinations of batteries each of $24 \mathrm{~V}$ and $150 \mathrm{Ah}$ capacity were considered. 21 batteries were used in series in order to achieve the desired voltage level of $500 \mathrm{~V}$ in each area. Further 20 parallel rows, 10 parallel rows and 4 parallel rows of these series connected batteries were used to achieve the desired current ratings of Area 1, Area 2 and Area 3 respectively. 

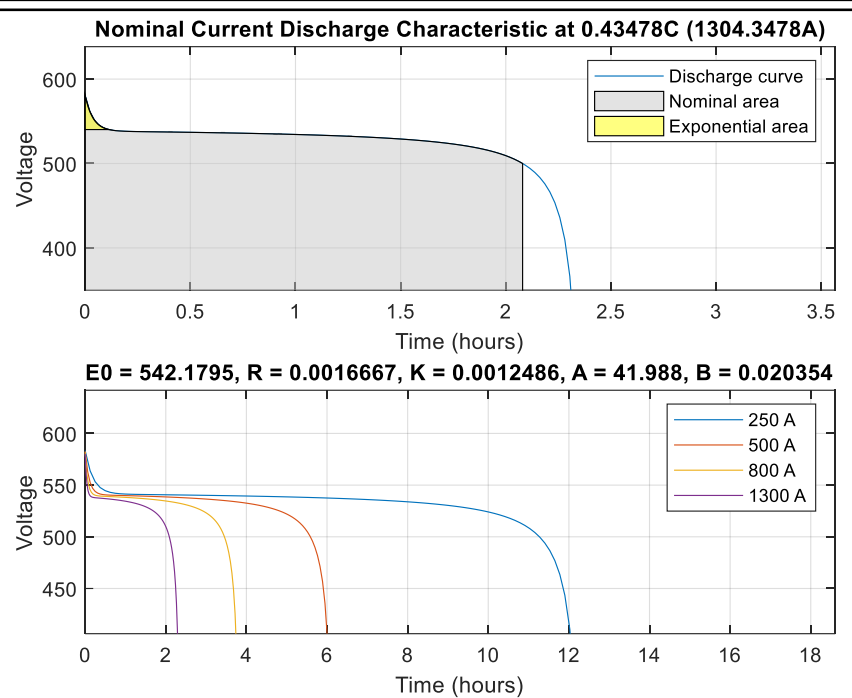

(a)
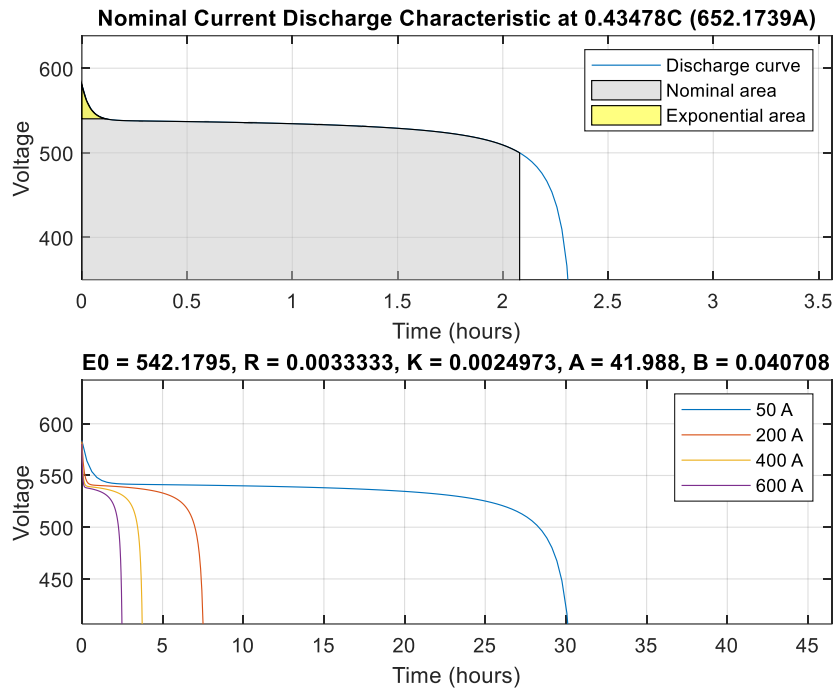

(b)
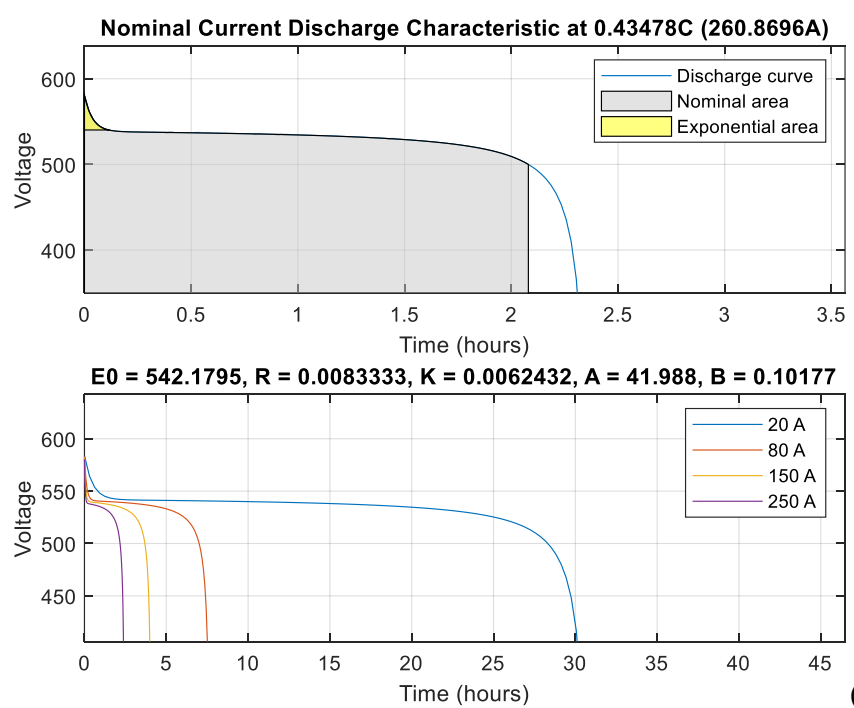

(c)

Fig. 5: Discharge characteristics of the battery system under nominal conditions (a) 1MW PV system (area 1), (b) $500 \mathrm{KW}$ PV system (area 2), (c) $200 \mathrm{KW}$ PV system (area 3).

D. Control of Voltage Source Inverter (VSI)

VSI is used to convert the DC voltage into multilevel three phase PWM signal. LC filter is used further to convert the PWM signal into an AC voltage with a frequency of 50Hz. All three areas used same 3-phase voltage 
at load side. DC voltage was converted into three phase AC voltage with phase-phase peak voltage at $565 \mathrm{~V}_{\text {peak, ph- }}$ ph $\left(400 \mathrm{~V}_{\text {rms, ph-ph }}\right)$. Figure 7 shows the control scheme employed in each area for VSI. Further, 3 arm 6 pulses bridges were used as VSI in each area.

\section{E. Diesel Generator Set ON/OFF Control}

One of the major challenges with renewable systems is their dependency on the environment conditions. During night time or cloudy weather, the PV panels will not be able to generate adequate power and the energy storage system could be drained completely if these conditions remain for longer duration of time. So, in order to avoid or reduce blackout time, diesel generators (DG) are also used along with the PV system as a backup power source in all three areas. In order to minimize the usage of DG sets, another control scheme is employed to control the operation of DG sets.

Figure 8 shows the logical flow chart of the control scheme for DGs. Operation of DGs depends upon the state of charge (SOC) of battery system. DGs turned ON when SOC goes below $25 \%$ during discharging cycle and become OFF when SOC goes up 30\% during the charging cycle of battery system. During the entire operation of DGs, VSI gets cut-off from the load side.

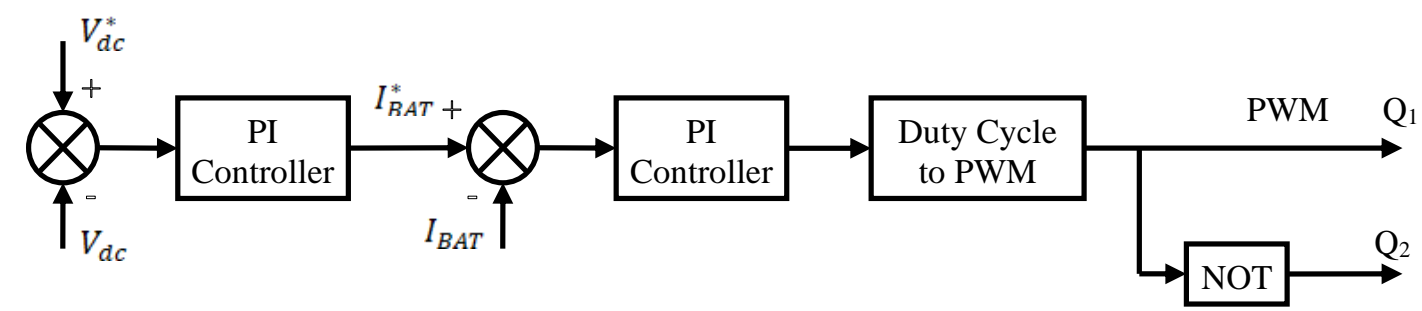

Fig. 6: Battery charging/discharging controller for bidirectional dc-dc converter.

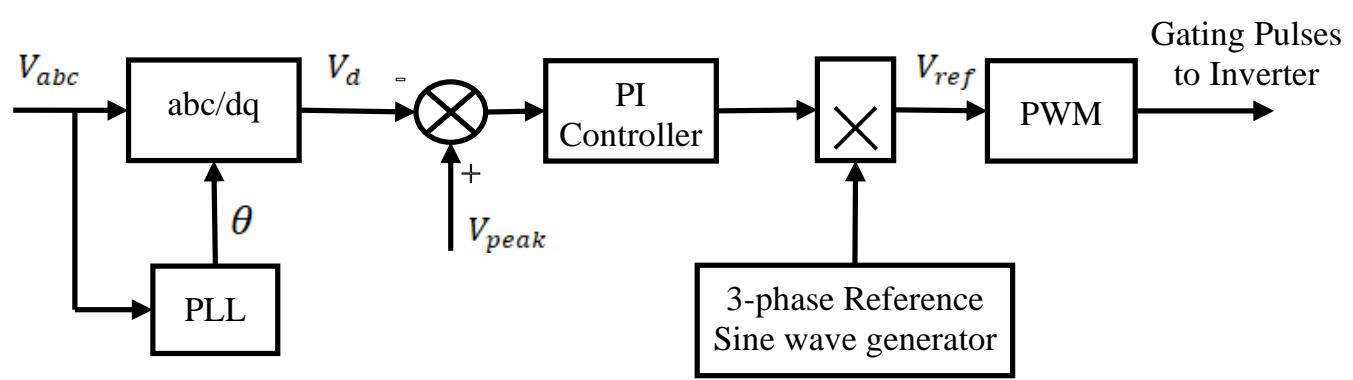

Fig. 7: Control scheme for PWM inverter.

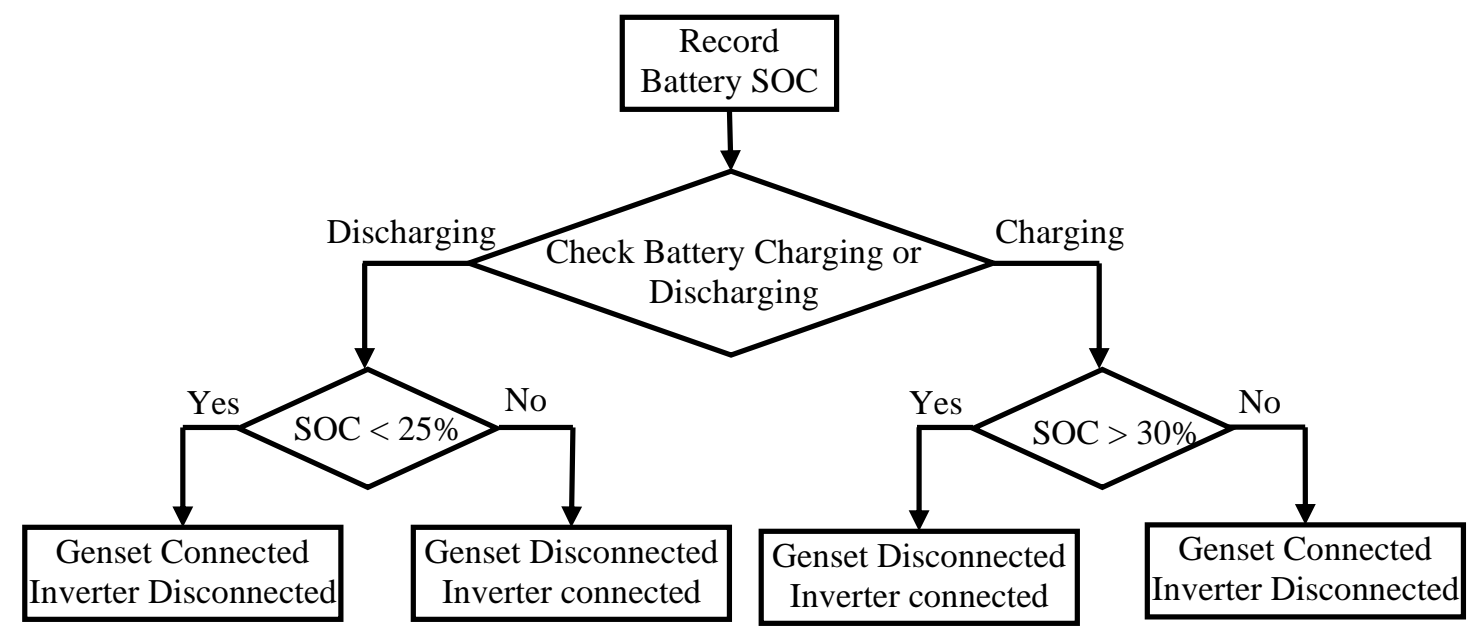

Fig. 8: Generator set ON/OFF control scheme.

\section{CONTROL SCHEME FOR MICROGRID INTERCONNECTION}

Interconnection between different areas is shown by Fig. 2. Prime objective of the islanded microgrid system is to run the entire system as much as possible only on the renewable energy available from the sun. Hence, in Area 1 and Area 2, power generated from the PV system is deducted from the instantaneous power being consumed at the load in order to compute the availability of the excess solar power. This can be explained mathematically by Eq. (1) and (2) for Area 1 and Area 2 respectively. 


\section{$P_{\text {excess }, 1}=P_{p v, 1}-P_{\text {load }, 1}$}

$P_{\text {excess }, 2}=P_{p v, 2}-P_{\text {load }, 2}$

where, $P_{\text {excess }}$ is the excess power available from Area 1 and 2, $P_{p v}$ is the total solar power generated and $P_{\text {load }}$ is total instantaneous power being consumed at load.

Area 3 supplies power to the critical loads in the forward operating base and its power requirement is to be fulfilled under any circumstances as has important and critical equipment. In order to ensure availability of power to the forward operating base in Area 3, in the present work power is re-routed to the area in case there is a deficiency of generated solar power at Area 3. Extra solar power required by the area can be depicted by Eq. (3)

$$
P_{\text {required }, 3}=P_{p v, 3}-P_{\text {load }, 3}
$$

Power co-ordination control strategy as shown in Fig. 2, decides the conditions under which power can be routed to Area 3 from Area 1 and Area 2. This control scheme takes information about $P_{\text {required,3 }}$ from Area 3 and excess power available at Area $1\left(P_{\text {excess }, 1}\right)$ and $2\left(P_{\text {excess }, 2}\right)$. Further, depending upon the situation it gives control commands to the breakers of each area as shown in Fig. 2. This section further explains the control scheme employed to manage the power flow among different areas depending upon the mode of operation.

\section{A. Normal Mode of Operation}

In normal mode of operation, power generated from the PV system in each area is enough to supply power to their corresponding loads. In the normal mode of operation, all circuit breakers at each area remain in OFF condition and each area function as isolated standalone microgrid system.

\section{B. Power Sharing Mode}

In this mode of operation, extra solar power generated at Area 1 and Area 2 is shared with Area 3. As mentioned above Area 1 and 2 are bases in depth areas and Area 3 is a forward operating base which is difficult to access and are susceptible to outages. Geographical conditions also vary with distances. So, in this mode of operation if PV system available at Area 3 does not generate adequate solar power as compared to load demand then power can be routed from Area 1 and Area 2 by turning ON the circuit breakers of each area.

\section{Emergency Mode}

Forward operating bases of Armed Forces are located towards the end of transmission systems and vulnerable to outages both by vagaries of weather like landslides, avalanches, storms, heavy rains or by action of adversary's actions like attacks. As the forward bases have critical equipment like weapon control systems, surveillance systems, communication systems, sensors etc, their power requirements are critical and have to be ensured under all circumstances. At many forward operating bases in remote areas, supplying fuel for generators is very expensive in terms of resources. In this work authors have proposed a power routing algorithm to thwart such challenges. the power control strategy block is programmed to ensure that the energy needs of Area 3 are satisfied. In this algorithm, if there is an outage in Area 3 then an emergency alarm will be activated. After the activation of emergency alarm (EMA), power from Area 1 and Area 2 will be routed to Area 3 by turning on their respective breakers. In this case, non-critical loads in Area 1 and Area 2 will be turned OFF immediately and excess power will be made available to supply the forward operating base in Area 3 .

Figure 9 shows the logical flow chart of the proposed power co-ordination algorithm in an Emergency mode in the networked microgrid in forward bases. 


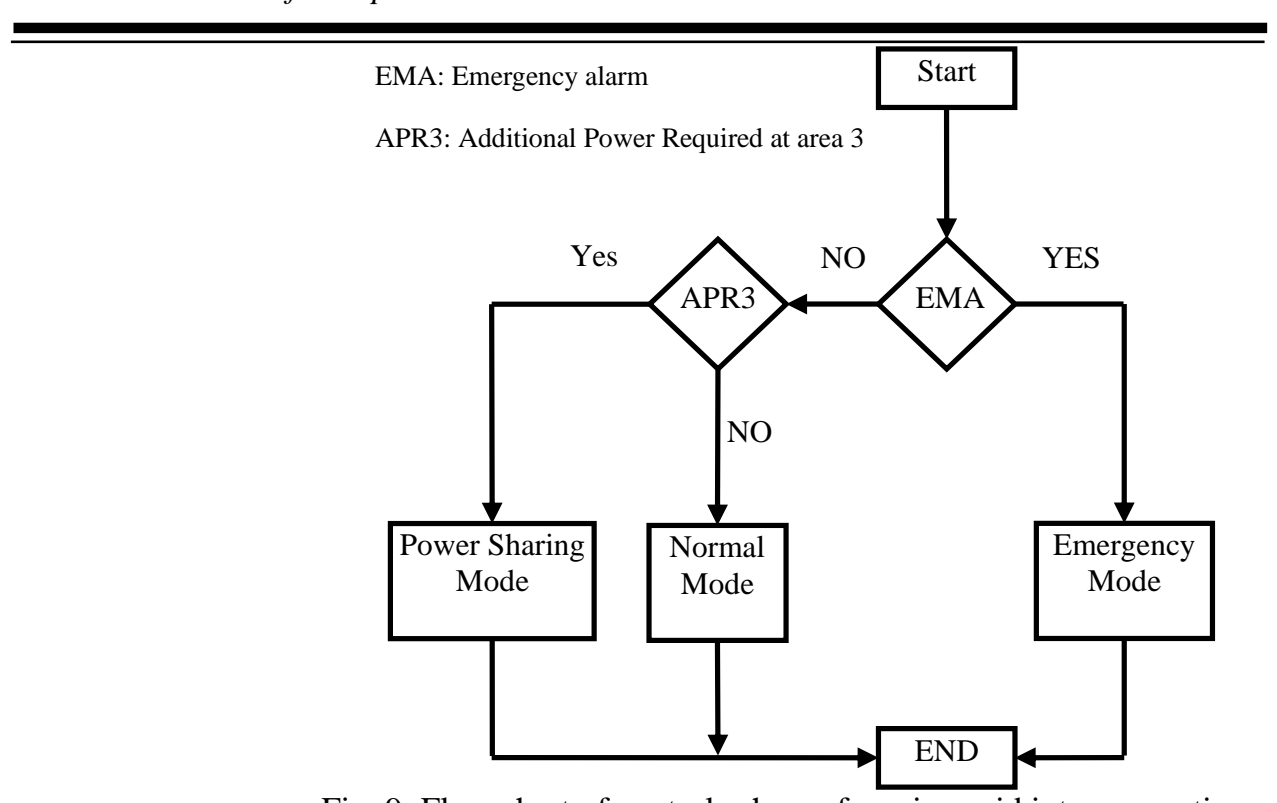

Fig. 9: Flow chart of control scheme for microgrid interconnections.

\section{Results}

The proposed interconnected islanded microgrid system of army deployment has been simulated and verified with MATLAB 2018. The system was simulated in all three mode of operation: (i) normal mode, (ii) power sharing mode and (iii) emergency mode. This section presents the detailed simulation results obtained from this study. 


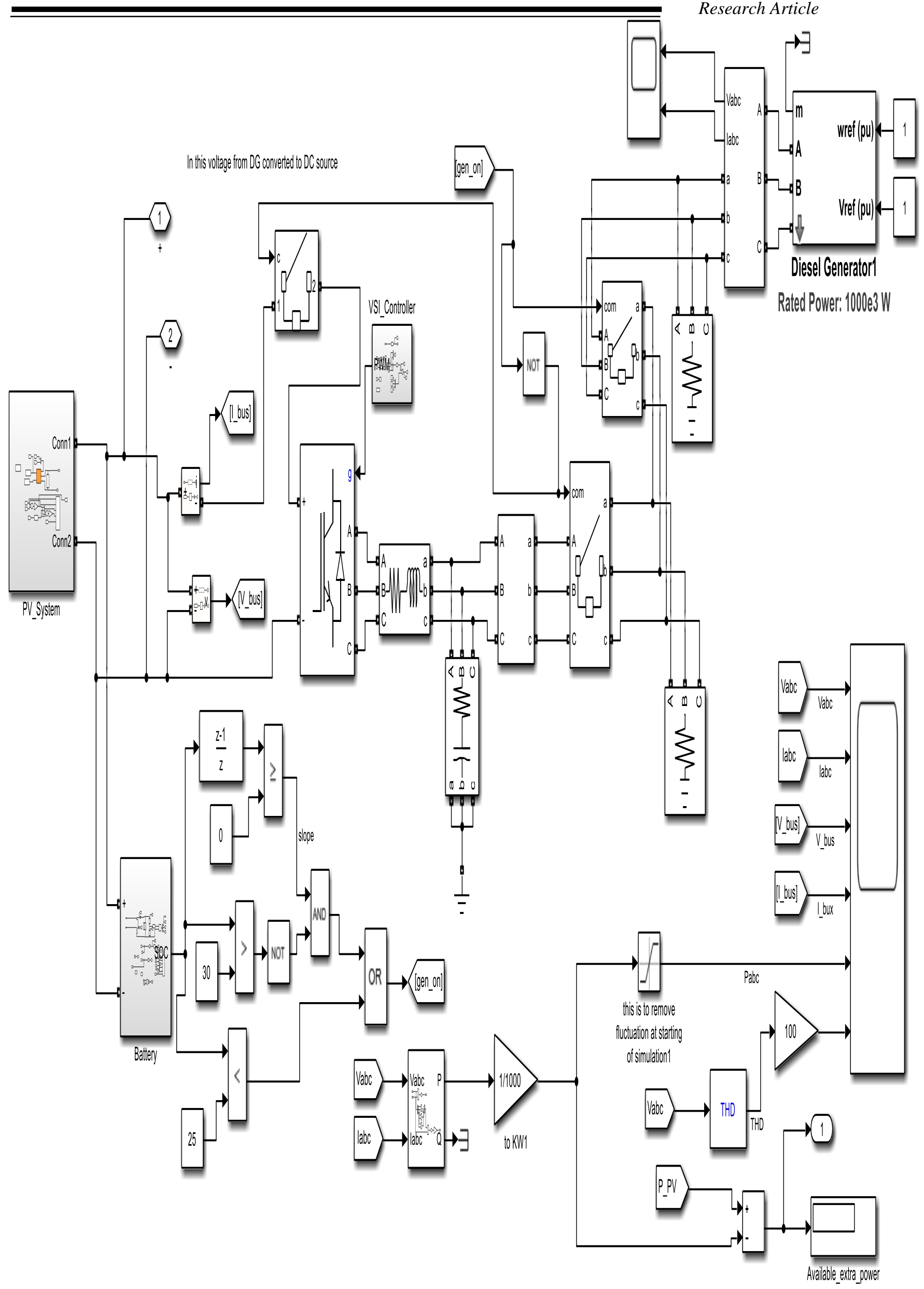

Fig. 10: Simulink design of an area. 


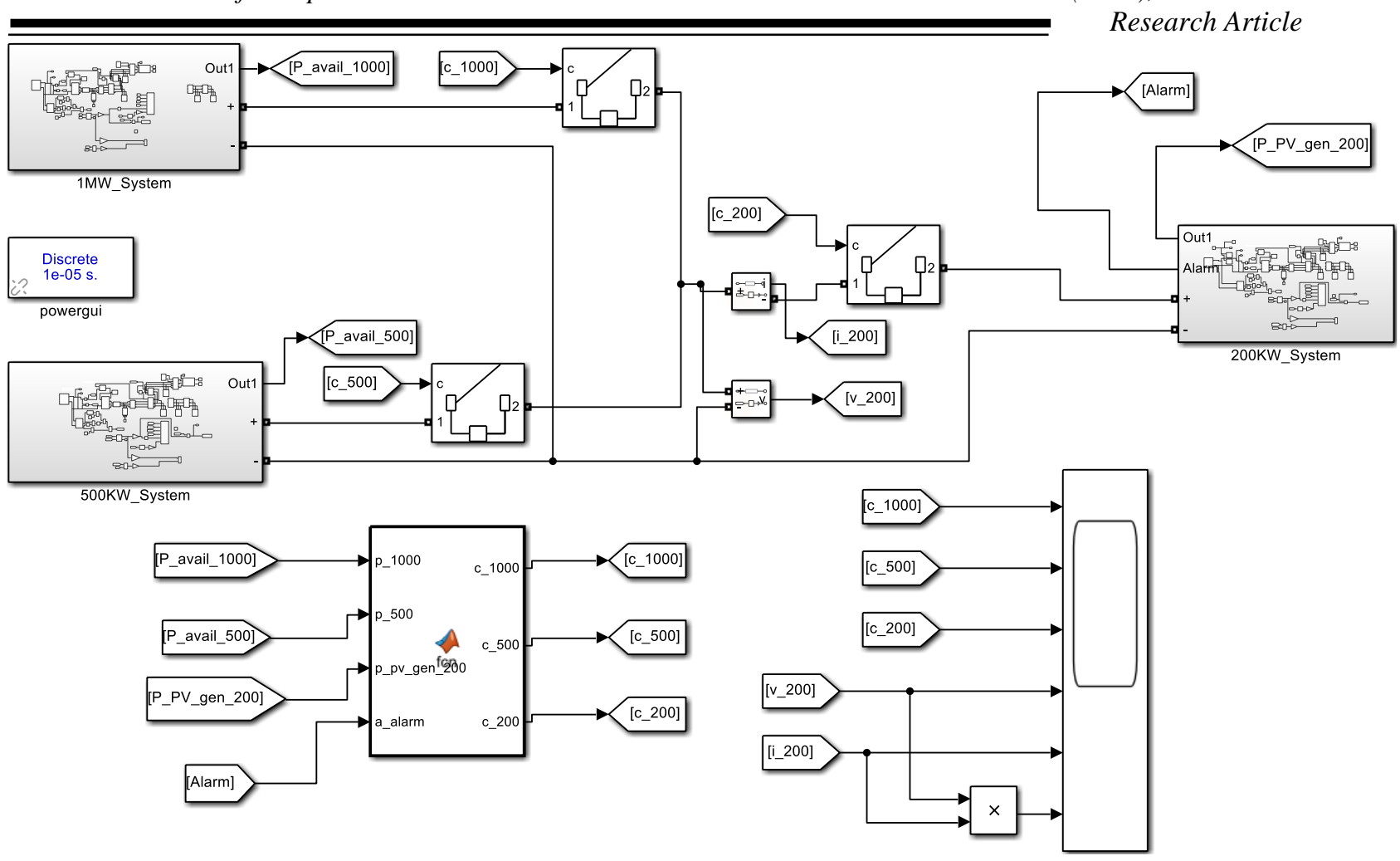

Fig. 11: Simulink design of complete system.

\section{A. Normal Mode Operation}

In the normal mode of operation all three microgrids at Areas 1, 2 and 3 operate normally and provide power to their specific areas. Area 1, Area 2 and Area 3 were supplying power to the $800 \mathrm{KW}, 300 \mathrm{KW}$ and $100 \mathrm{KW}$ of load respectively. Fig. 12(a) shows the irradiance profile used for this simulation. Similar irradiance profile was used for all three areas. Fig. 12(b) shows the PV power generated at all three sites and Fig. 12(c) shows the instantaneous power delivered to the load at all three areas.

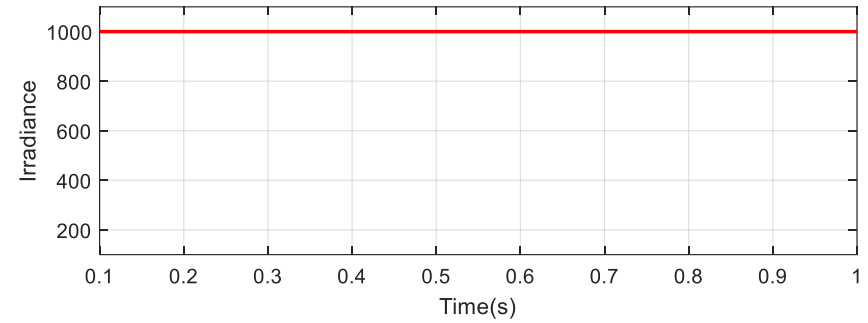

(a)

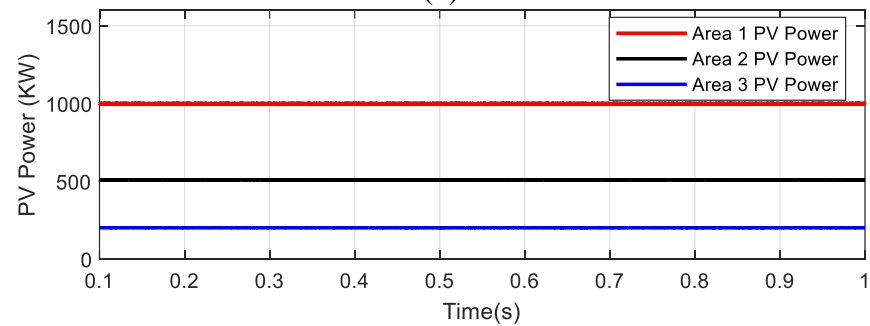

(b)

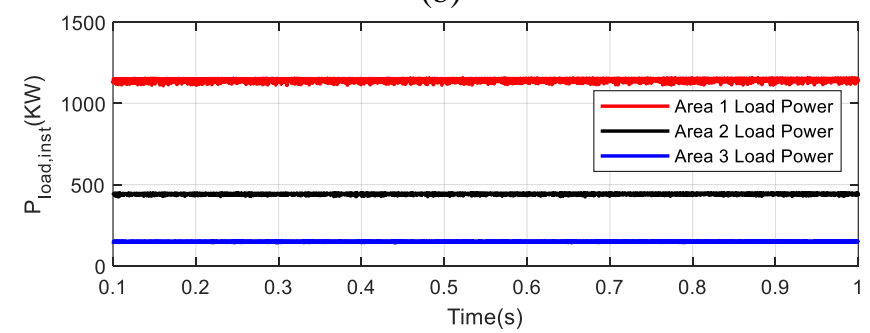

(c) 


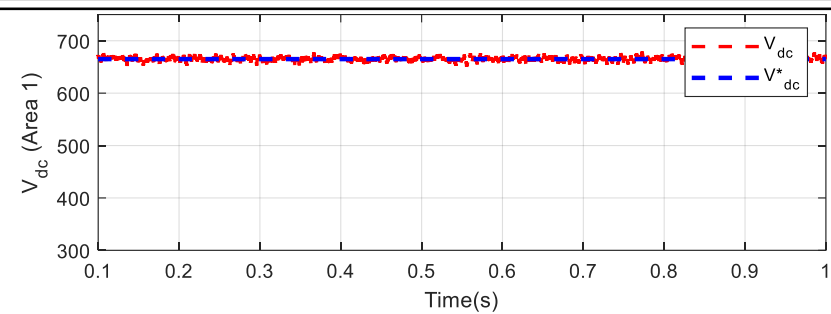

(d)

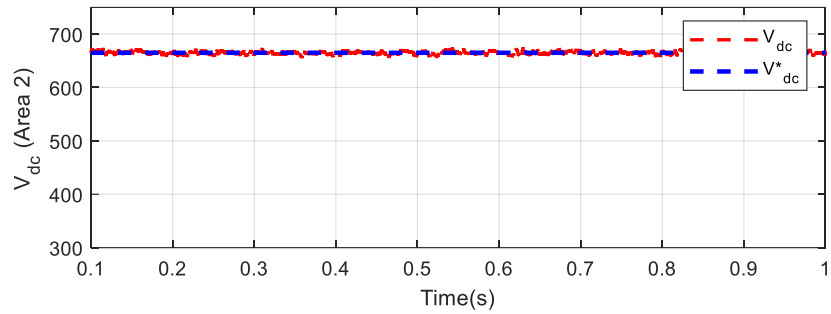

(e)

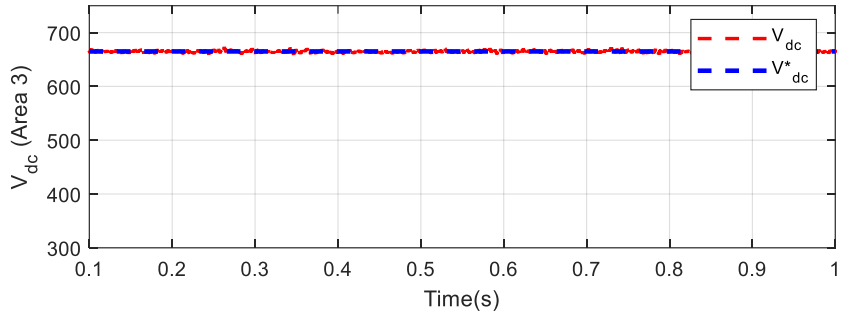

(f)
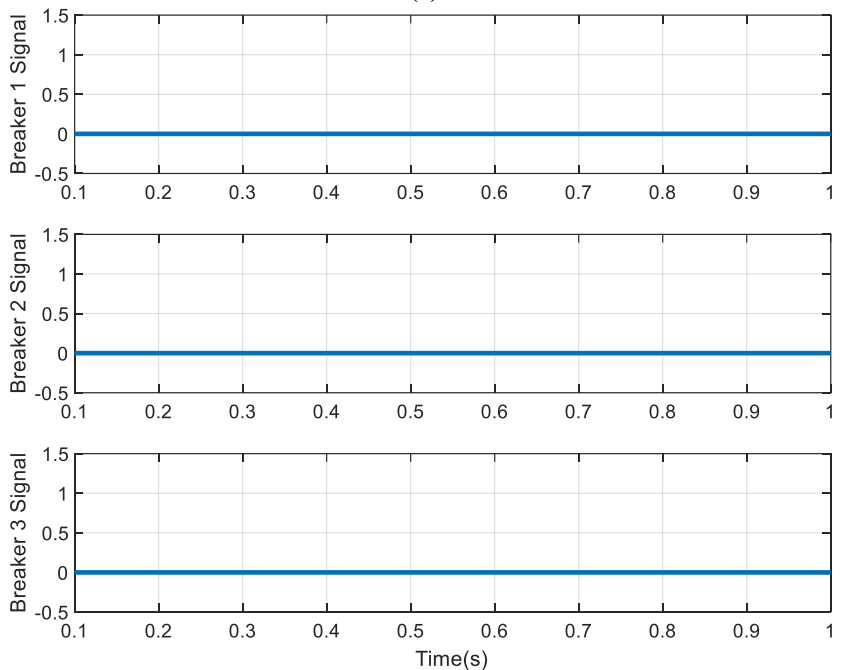

(g)

Fig. 12: (a) Solar irradiance profile, (b) Generated PV power of each area, (c) Power delivered to the load of each area, (d) DC bus voltage of Area 1, (e) DC bus voltage of Area 2, (f) DC bus voltage of Area 3, (g) Command signal generated for all three breakers.

Figure 12(d)-(f) shows the dc link voltage at all three areas and from fig. it is clear that all three areas are working satisfactory during normal mode of operation. Further, Fig. 12(g) shows the command signal sent to all three breakers as shown in Fig. 2. As there is no extra power requirement from the Area 3, 0 command or OFF command is generated by the power co-ordination control strategy block.

\section{B. Power Sharing Mode}

In the power sharing mode, Area 3 requires additional power and the same has been fulfilled by Area 1 and Area 2. Several results obtained from this study are shown in this section. Fig 13(a) and 13(b) shows the solar irradiance profile at Area 1,2 and Area 3 respectively. For this simulation, solar irradiance falls to 600 at 0.2 sec. Fig. 13(c) shows the PV power generated, as solar irradiance drops at 0.2 sec, power generated by Area 3 also drops and this generates the additional power requirement from Area 1 and Area 2 as per our proposed algorithm. Fig. 13(d) shows the instantaneous power supplied to the load during this entire simulation. Fig. 13(e)-(g) shows the DC-link voltage at each area during the simulation time and from these figures it is clear that entire DC-link remain stable and power is shared in this mode of simulation. Fig. 13(h) shows the commands given to the 
breakers. It is seen that all breakers turned $\mathrm{ON}$ as soon as there is a requirement of excess solar power at area 3 at $0.2 \mathrm{sec}$.

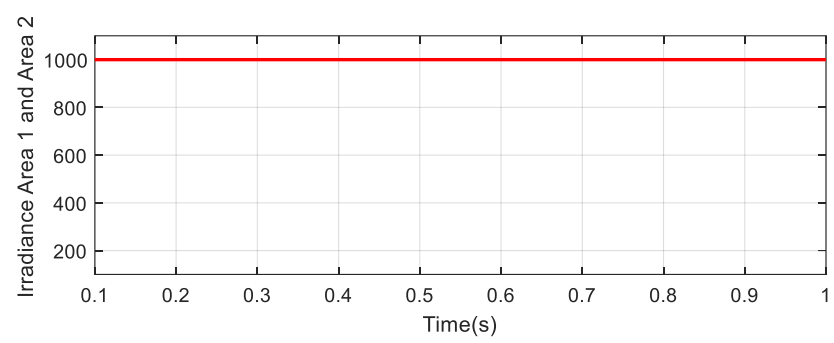

(a)

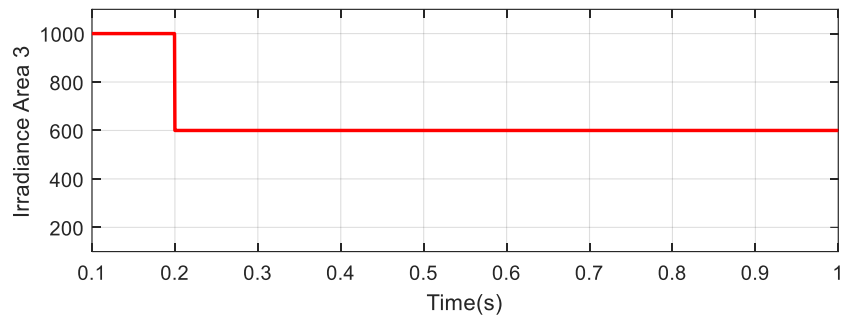

(b)

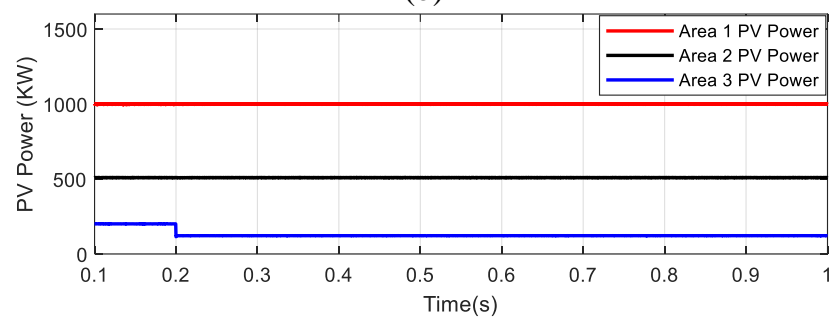

(c)

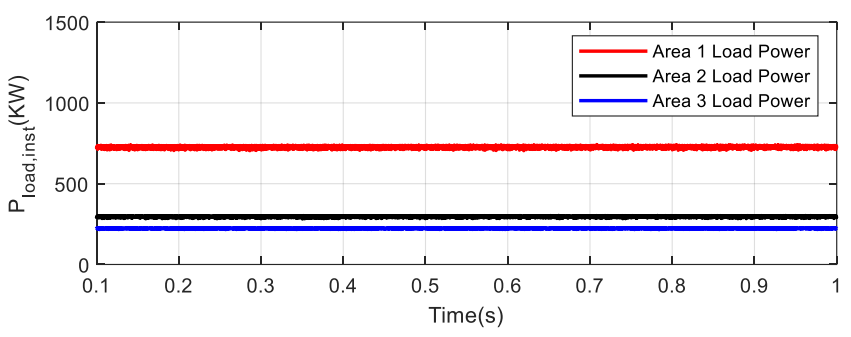

(d)

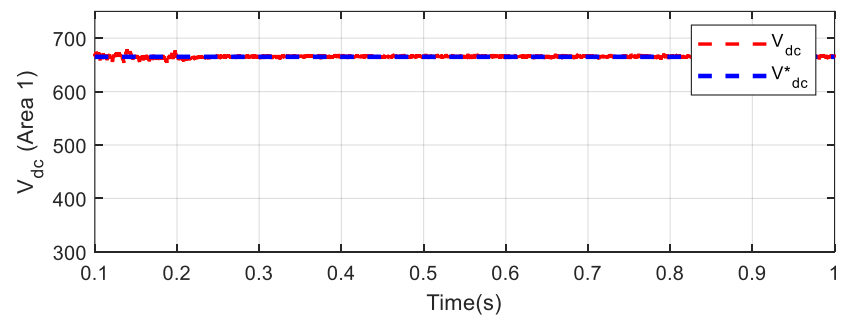

(e)

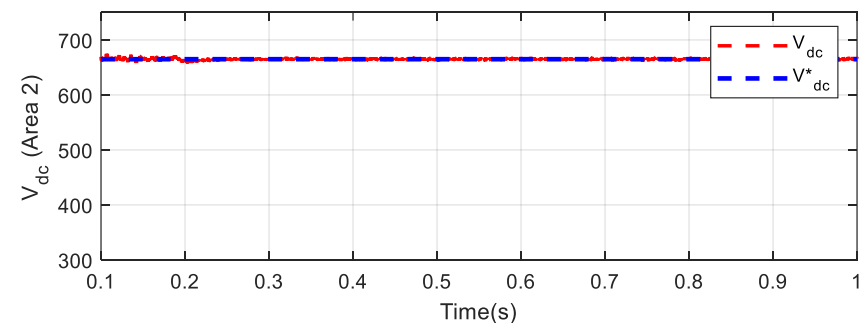

(f) 


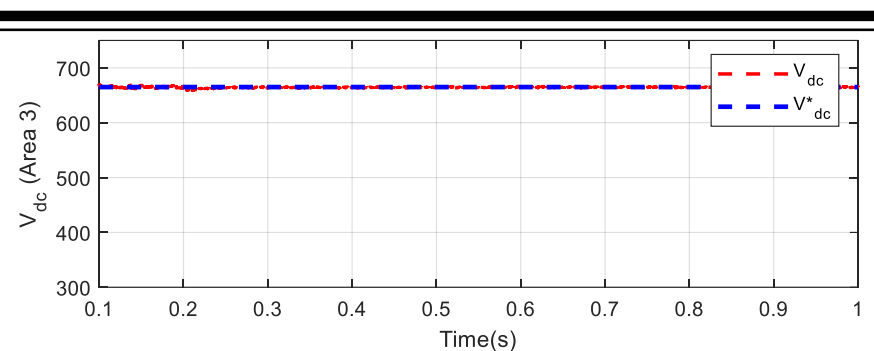

$(\mathrm{g})$
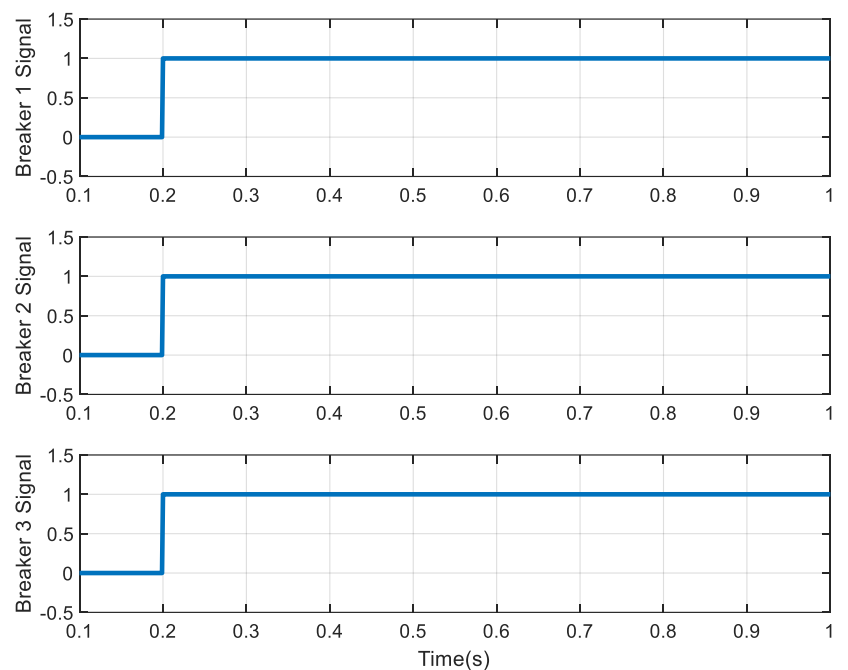

(h)

Fig. 13: (a) Irradiance at area 1 and area 2, (b) Solar irradiance at area 3, (c) PV power generated at each area, (d) Instantaneous power delivered to the load at each area, (e) DC-link voltage at area 1, (f) DC-link voltage at area 2, (g) DC-link voltage at area 3, (h) Command signal generated for all three breakers.

\section{Emergency Mode Operation}

This section presents the results obtained during emergency mode of operation. As stated earlier, in a case of emergency at Area 3, power will be directed to critical loads of Area 3 instantly. During the emergency situation non-critical loads at Area 1 and Area 2 will be cut-off and only critical loads at Area 1 and 2 will be functional. In this simulation, critical loads of $300 \mathrm{KW}$ and $100 \mathrm{KW}$ were connected at Area 1 and Area 2 respectively. Emergency situation is simulated by raising an alarm as soon as there is an outage or criticality in Area 3.

Fig. 14(a) shows the irradiance profile during the entire simulation. Fig. 14(b) shows the alarm signal. In this simulation emergency situation is simulated at $0.3 \mathrm{sec}$ by raising the alarm signal to 1 . Fig. 14(c) shows the PV power generated at all three sites. At $0.3 \mathrm{sec}$, PV power drops to 0 at Area 3 after a simulated outage which could be due to natural calamity or an attack on its power generation. Fig. 14(d) shows the instantaneous power delivered to the load at all three areas. From this figure it can be seen that, as soon as alarm turns ON, redundant load at Area 1 and Area 2 gets disconnected. It is represented by the reduction in the instantaneous power delivered to the load. It can be seen from the Fig. 14(d) that critical loads at Area 3 are maintained and keep getting adequate power during the entire simulation time. It indicates that power from Area 1 and Area 2 gets directed towards the Area 3. Fig. 14(e)-(g) shows the DC-link voltage of each areas. It can be inferred from the graphs that DC-link remain stable during this entire simulation time. Fig. 14(h) shows the command signal given to all three breakers as shown in Fig. 2.

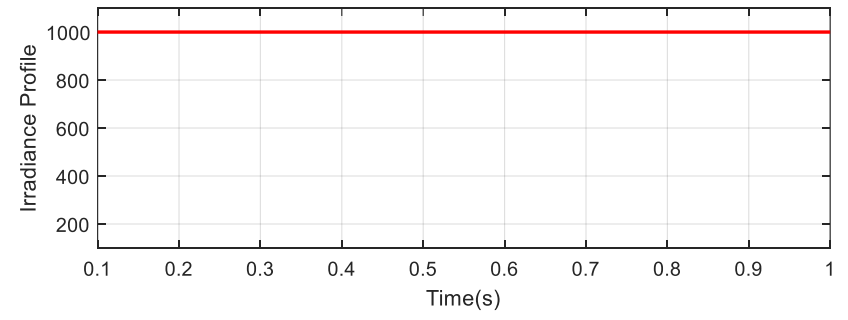

(a) 


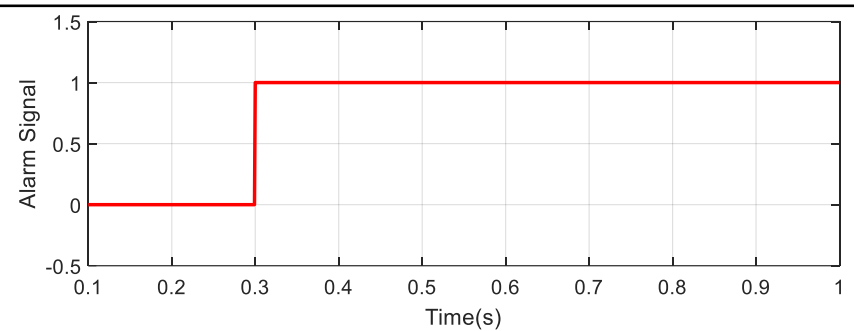

(b)

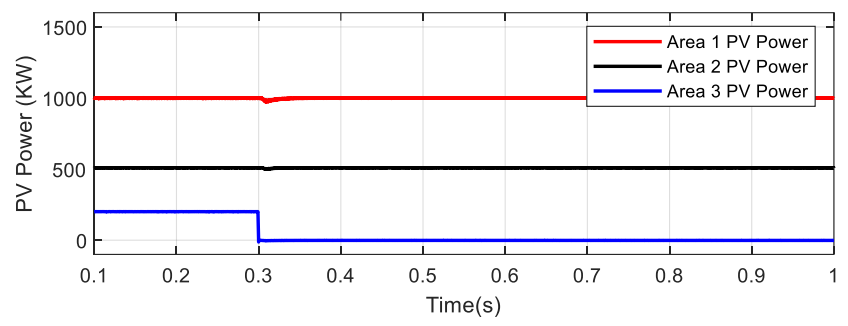

(c)

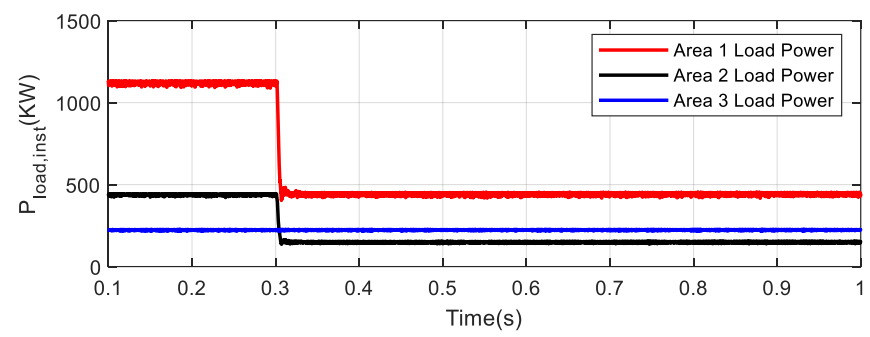

(d)

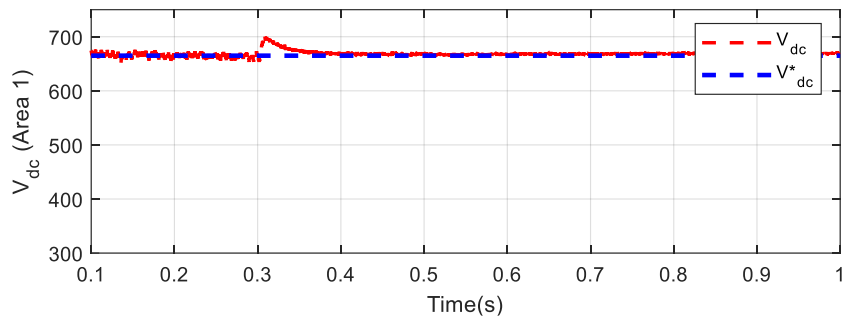

(e)

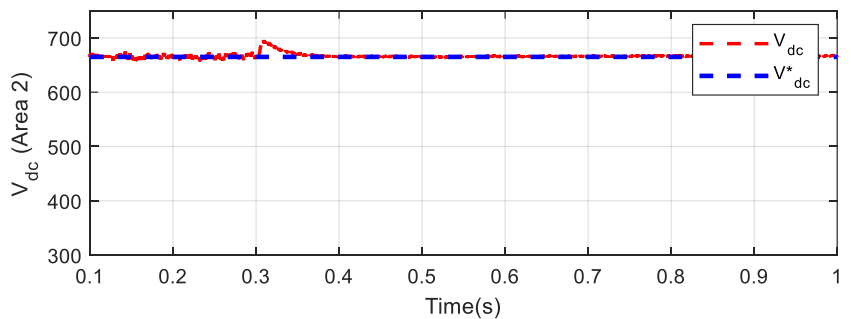

(f)

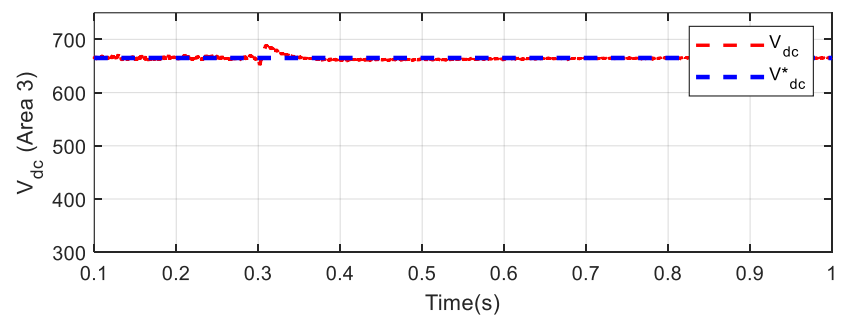

(g) 

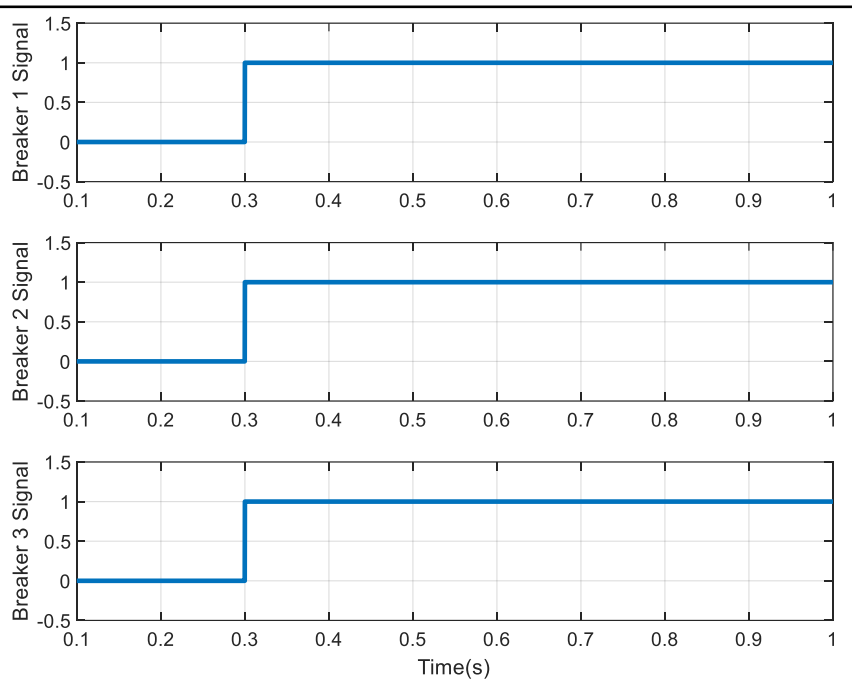

(h)

Fig. 14: (a) Irradiance profile, (b) Alarm signal, (c) PV power generated at each area, (d) Instantaneous power delivered to the load at each area, (e) DC-link voltage at area 1, (f) DC-link voltage at area 2, (g) DC-link voltage at area 3, (h) Command signal generated for all three breakers.

\section{ConClusion}

In this work three different microgrids with different capacity have been designed and interconnected in remote bases and the network operation is simulated for different operating conditions in which the critical power requirement of a forward operating base by load sharing algorithm has been ensured. Further, microgrids of each area were interconnected with the help of DC bus for sharing power to critical load in an inaccessible forward base which requires fuel to be carried for generators thereby reducing huge logistic costs and reducing carbon footprint. Simulation was also done to mitigate the emergency situation at critical load site by routing the power from other two areas. Working of the entire system and power co-ordination control strategy has been shown with the help of simulated study. In future work, artificial intelligence scheme can be employed for such networks.

\section{REFERENCES}

[1] F. S. Gazijahani and J. Salehi, "Stochastic multi-objective framework for optimal dynamic planning of interconnected microgrids," IET Renew. Power Gener., vol. 11, no. 14, pp. 1749-1759, 2017.

[2] A. G. Anastasiadis, A. G. Tsikalakis, and N. D. Hatziargyriou, "'Operational and environmental benefits due to significant penetration of microgrids and topology sensitivity," in Proc. IEEE PES General Meeting, Jul. 2010, pp. 1-8.

[3] M. Shahidehpour, Z. Li, S. Bahramirad, Z. Li, and W. Tian, "Networked microgrids: Exploring the possibilities of the IIT-Bronzeville grid," IEEE Power and Energy Magazine, vol. 15, no. 4, pp. 63-71, Jul. 2017.

[4] M. Ross, C. Abbey, F. Bouffard, and G. Jos, "Multiobjective opti- mization dispatch for microgrids with a high penetration of renewable generation," IEEE Trans. Sustainable Enery, vol. 6, no. 4, pp. 1306- 1314, Oct. 2015.

[5] M. Fathi and H. Bevrani, "Statistical cooperative power dispatching in interconnected microgrids," IEEE Trans. Sustainable Enery, vol. 4, no. 3, pp. 586-593, Jul. 2013.

[6] A. M. Jadhav and N. R. Patne, "Priority-based energy scheduling in a smart distributed network with multiple microgrids," IEEE Trans. Ind. Informat., vol. 13, no. 6, pp. 3134-3143, Dec. 2017.

[7] M. R. Sandgani and S. Sirouspour, "Priority-based microgrid energy management in a network environment," IEEE Trans. Sustainable Enery, vol. 9, no. 2, pp. 980-990, Apr. 2018.

[8] Z. Wang, B. Chen, J. Wang, M. M. Begovic, and C. Chen, "Coordinated energy management of networked microgrids in distribution systems," IEEE Trans. Smart Grid, vol. 6, no. 1, pp. 45-53, Jan. 2015.

[9] H. Gao, J. Liu, L. Wang, and Z. Wei, "Decentralized energy manage- ment for networked microgrids in future distribution systems," IEEE Trans. Power Syst., vol. PP, no. 99, pp. 1-1, 2017.

[10] R. Zamora and A. K. Srivastava, "Multi-layer architecture for voltage and frequency control in networked microgrids," IEEE Trans. Smart Grid, vol. PP, no. 99, pp. 1-1, 2017. 
[11] W. Yuan, J. Wang, F. Qiu, C. Chen, C. Kang, and B. Zeng, "Robust optimization-based resilient distribution network planning against natural disasters," IEEE Trans. Smart Grid, vol. 7, no. 6, pp. 28172826, Nov. 2016.

[12] E. Harmon, U. Ozgur, M. H. Cintuglu, R. de Azevedo, K. Akkaya, and O. A. Mohammed, "The internet of microgrids: A cloud-based framework for wide area networked microgrids," IEEE Trans. Ind. Informat., vol. 14, no. 3, pp. 1262-1274, Mar. 2018.

[13] S. Abhinav, H. Modares, F. L. Lewis, F. Ferrese, and A. Davoudi, "Synchrony in networked microgrids under attacks," IEEE Trans. Smart Grid, vol. PP, no. 99, pp. 1-1, 2017.

[14] J. Matamoros, D. Gregoratti, and M. Dohler, “Microgrids energy trading in islanding mode," in Proc. IEEE 3rd Int. Conf. Smart Grid Commun. (SmartGridComm), Nov. 2012, pp. 49-54.

[15] E. J. Ng and R. A. El-Shatshat, "Multi-microgrid control systems (MMCS),' in Proc. IEEE PES General Meeting, Jul. 2010, pp. 1-6.

[16] G. Zheng and N. Li, "Multi-agent based control system for multimicrogrids,"' in Proc. Int. Conf. Comput. Intell. Softw. Eng., Dec. 2010, pp. 1-4.

[17] G. N. Korres, N. D. Hatziargyriou, and P. J. Katsikas, "State estimation in multi-microgrids," Eur. Trans. Elect. Power, vol. 21, no. 2, pp. 1178-1199, Mar. 2011.

[18] A. G. Madureira, J. C. Pereira, N. J. Gil, J. A. P. Lopes, G. N. Korres, and N. D. Hatziargyriou, “Advanced control and management functionalities for multi-microgrids,'” Eur. Trans. Elect. Power, vol. 21, no. 2, pp. 1159-1177, Mar. 2011.

[19] Z. Wang, B. Chen, J. Wang, and C. Chen, "Networked microgrids for self-healing power systems," IEEE Trans. Smart Grid, vol. 7, no. 1, pp. 310-319, Jan. 2016.

[20] Y. Li, P. Zhang, and P. B. Luh, "Formal analysis of networked microgrids dynamics," IEEE Trans. Power Syst., vol. PP, no. 99, pp. 1-1, 2017.

[21] X. Hu and T. Liu, "Co-optimisation for distribution networks with multi- microgrids based on a two-stage optimisation model with dynamic electricity pricing," IET Gener. Transm. Distrib., vol. 11, no. 9, pp. 22512259, 2017.

[22] H. Lotfi and A. Khodaei, "AC versus DC microgrid planning," IEEE Trans. Smart Grid, vol. 8, no. 1, pp. 296-304, Jan 2017.

[23] Z. Wang and J. Wang, "Self-healing resilient distribution systems based on sectionalization into microgrids," IEEE Trans. Power Syst., vol. 30, no. 6, pp. 3139-3149, Nov. 2015.

[24] Z. Wang, B. Chen, J. Wang, and C. Chen, "Networked microgrids for self-healing power systems," IEEE Trans. Smart Grid, vol. 7, no. 1, pp. 310-319, Jan. 2016.

[25] S. Backhaus, L. Dobriansky, S. Glover, C.-C. Liu, P. Looney, S. Mashayekh, A. Pratt, K. Schneider, M. Stadler, M. Starke, J. Wang, and M. Yue, "Networked microgrids scoping study," Los Alamos National Laboratory, Tech. Rep., Jan. 2016.

[26] A. Arif and Z. Wang, "Networked microgrids for service restoration in resilient distribution systems," IET Gener. Transm. Distrib., vol. 11, no. 14, pp. 3612-3619, 2017

[27] G. Liu, M. R. Starke, B. Ollis, and Y. Xue, "Networked microgrids scoping study," Oak Ridge National Laboratory, Tech. Rep., Oct. 2016.

[28] C.P.S. Pasricha, R. Gupta and R. Walawalkar, "Stand alone 1-MW microgrid for remote locations of armed forces with PV-Battery-Diesel generator," International Journal of Engineering and Advanced Technology (IJEAT), vol. 10, no. 1, pp. 350-358, 2020. 